\title{
Simultaneous Determination of Six Active Components in Oviductus Ranae via Quantitative Analysis of Multicomponents by Single Marker
}

\author{
Shihan Wang, ${ }^{1}$ Yang Xu, ${ }^{2}$ Yanwei Wang, ${ }^{1}$ Huailei Yang, ${ }^{3}$ Zuying Lv, \\ Xiangqun Jin, ${ }^{1}$ and Yongsheng Wang ${ }^{1}$ \\ ${ }^{1}$ School of Pharmacy, Jilin University, Changchun, Jilin 130021, China \\ ${ }^{2}$ Department of Pharmaceutics, Changchun Medical College, Changchun, Jilin 130021, China \\ ${ }^{3}$ Chinese Institute of Jilin Ginseng, Changchun, Jilin 130021, China \\ Correspondence should be addressed to Xiangqun Jin; jinxq@jlu.edu.cn and Yongsheng Wang; 165690808@qq.com
}

Received 8 March 2017; Revised 30 July 2017; Accepted 28 August 2017; Published 24 October 2017

Academic Editor: Antony C. Calokerinos

Copyright (c) 2017 Shihan Wang et al. This is an open access article distributed under the Creative Commons Attribution License, which permits unrestricted use, distribution, and reproduction in any medium, provided the original work is properly cited.

A method, quantitative analysis of multicomponents by single marker (QAMS), was established in this article to investigate the quality control of a traditional Chinese medicine, Oviductus Ranae. 7-Hydroxycholesterol, 7-ketocholesterol, 4-cholesten-3-one, stigmasterol, 7-dehydrocholesterol, and cholesterol were selected as the indexes of quality evaluation of Oviductus Rana. The determination was achieved on an Agilent HC-C18 column $(4.6 \mathrm{~mm} \times 250 \mathrm{~mm}, 5 \mu \mathrm{m})$ using methanol with water $(87: 13 \mathrm{v} / \mathrm{v})$ as mobile phase at the flow rate of $2.0 \mathrm{~mL} / \mathrm{min}$. Cholesterol was used as an internal standard to determine the relative correction factors between cholesterol and other steroidal constituents in Oviductus Ranae. The contents of those steroidal constituents were calculated at the same time. To evaluate the QAMS method, an external standard method was used to determine the contents of six steroidal constituents. No significant difference was observed when comparing the quantitative results of QAMS with the results of external standard method. The proposed QAMS method was proved to be accurate and feasible based on methodological experiments. QAMS provided a simple, efficient, economical, and accurate way to control the quality of Oviductus Ranae.

\section{Introduction}

Oviductus Ranae, a traditional Chinese medicine (TCM), can be obtained from dry oviduct of female Rana temporaria chensinensis David [1]. It has increasingly attracted worldwide attention because of its effect on nourishing Yin and moistening lung, strengthening the spleen and stomach, nourishing the kidney, and strengthening the essence as well. Pharmacology study showed it also has curative effects such as antitussive, antiasthmatic, antiaging, and antifatigue effects and enhancing the efficacy of immunity [2-5]. The challenge preventing its clinical practice is the uncontrollable quality of Oviductus Ranae. Determination method for the components of Oviductus Ranae has not been introduced in Chinese Pharmacopoeia (Chp; 2015 edition). Current method for the quality control of Oviductus Ranae involves using single component or a marker compound as the internal standard substance [6-8]. However, high-quality standard compounds or references are quite expensive and relying on single component of quality control is insufficient. Therefore, establishing a low-cost, reliable, and efficient approach is significantly important.

Quantitative analysis of multicomponents by single marker (QAMS) has been regarded as an alternative to the quality control of TCMs [9-15]. The relative correction factor (RCF) of contents in Oviductus Ranae is calculated using the reference substance of each analyte [16-18]. The RCF of the other six analytes were determined. Their contents were calculated based on RCF. Steroidal constituents in Oviductus Ranae have significant pharmacological activities 


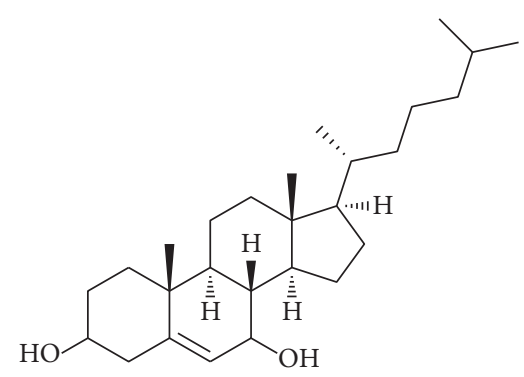

(1)

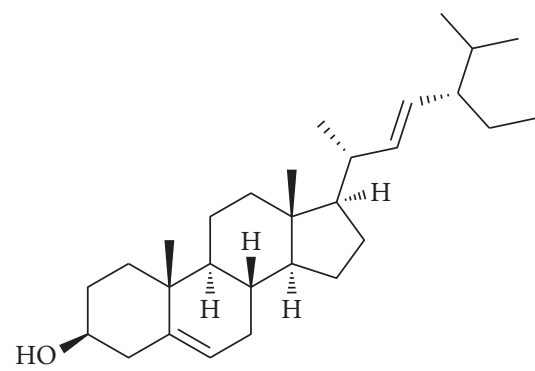

(4)

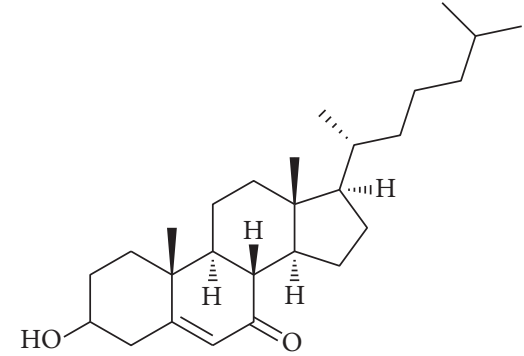

(2)

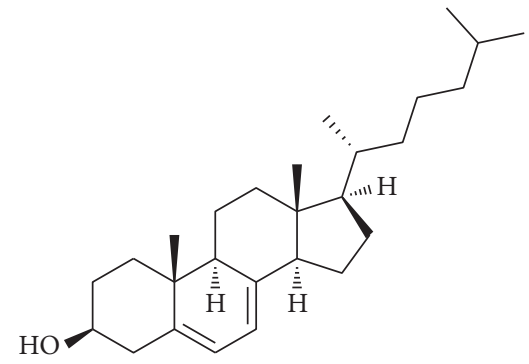

(5)

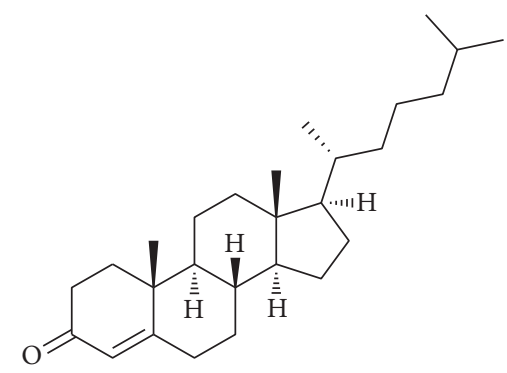

(3)

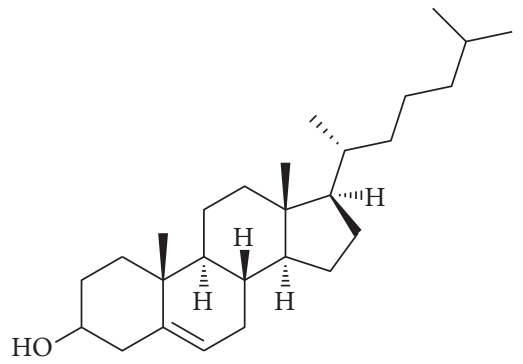

(6)

FIGURE 1: The chemical structures of six analytes: 7-hydroxycholesterol (1), 7-ketocholesterol (2), 4-cholesten-3-one (3), stigmasterol (4), 7-dehydrocholesterol (5), and cholesterol (6).

which are mainly exhibited on the aspects of antifatigue, immunity enhancement, antiaging, maintaining the balance of hormones. In addition, some steroids can be transformed into other steroid hormones with good activities through biological transformation [19-33]. To develop a QAMS method for the simultaneous determination of six active components in Oviductus Ranae, cholesterol was chosen as the internal standard substance. Six active steroidal components were selected as the indexes of quality evaluation of Oviductus Ranae (Figure 1).

\section{Experimental}

2.1. Instrument and Chromatographic Conditions. Chromatographic separation was achieved on Agilent 1260 high performance liquid chromatography (HPLC) equipped with DAD detector (G1315B), automatic sampling device (G1329B), Agilent Chemstation workstation, and Waters Alliance E2695. Another high performance liquid chromatography was equipped with $2489 \mathrm{UV}$ detector, automatic sampling device (E2695), and Empower workstation. Agilent HC-C18, Amethyst C18-P, and Eclipse XDB-C18 $(250 \mathrm{~mm} \times 4.6 \mathrm{~mm}$, $5 \mu \mathrm{m}$ ) were employed during the experiment under the following chromatographic conditions: the mobile phase was composed of methanol and water $(87: 13 \mathrm{v} / \mathrm{v})$ under the detection wavelength of $205 \mathrm{~nm}, 240 \mathrm{~nm}$, and $280 \mathrm{~nm}$ at the flow rate of $2.0 \mathrm{~mL} \cdot \mathrm{min}^{-1}$. The column temperature was maintained at $35^{\circ} \mathrm{C}$, and the injection volume was $10 \mu \mathrm{L}$. KQ$400 \mathrm{KDB}$ high power digital ultrasonic cleaner was purchased from Kunshan Ultrasonic Instrument Co. Ltd. RE-52-99 rotary evaporator was purchased from Shanghai Ya Rong Biochemical Instrument Factory. WP-UP-III-10 ultrapure water was purchased from Sichuan Water Treatment Equipment Co. Ltd.

2.2. Reagents and Materials. Cholesterol (batch number: 111618-200301) was purchased from China Food and Drug Verification Research Institute (Beijing, China). 4-Cholesten3-one (batch number: S45539-479) was purchased from American sigma company (USA). 7-Dehydrogenation cholesterol (batch number: CDCT-12115000) was purchsed from Dr. Ehrenstorfer (Germany). Stigmasterol (batch number: A0510) was purchased from Shanghai Yao Yun Biological Science and Technology Co., Ltd. 7-Ketocholesterol and 7-hydroxycholesterol were prepared by laboratory according to previous reports (content: more than or equal to 98\%) [34]. Fourteen batches of Oviductus Ranae were collected from different regions in China, which were conducted by Professor Dacheng Jiang from Changchun University of Traditional Chinese Medicine and proved to be dry oviduct of female Rana temporaria chensinensis David. The details were showed in Table 1. Methanol (Fisher, America) was of chromatographic grade, and other reagents (Beijing Chemical Industry Factory) were of analytical grade. Ultrapure water was prepared by water instrument WP-UP-III-10.

2.3. Preparation of Mixed Standard Solution. Substances of 7-hydrocholesteol, 7-ketocholesterol, 4-cholesten-3-one, 7dehydrogenation cholesterol, cholesterol, and stigmasterol were weighed precisely and dissolved into methanol to prepare standard solutions with the concentration of 1.579 $\times 10^{2} \mu \mathrm{g} / \mathrm{mL}, 32.525 \mu \mathrm{g} / \mathrm{mL}, 20.225 \mu \mathrm{g} / \mathrm{mL}, 9.775 \mu \mathrm{g} / \mathrm{mL}, 4.00$ 
TABLE 1: Batch and origin of Oviductus Ranae.

\begin{tabular}{lccc}
\hline NO. & Origin & Year & Batch \\
\hline S1 & Tonghua, Jilin Province & 2014 & 201401 \\
S2 & Tonghua, Jilin Province & 2014 & 201402 \\
S3 & Huadian, Jilin Province & 2015 & 201503 \\
S4 & Huadian, Jilin Province & 2015 & 201504 \\
S5 & Heihe, Heilongjiang Province & 2015 & 201505 \\
S6 & Dunhua, Jilin Province & 2015 & 201506 \\
S7 & Jingyu, Jilin Province & 2015 & 201507 \\
S8 & Jingyu, Jilin Province & 2015 & 201508 \\
S9 & Fangzheng, Heilongjiang Province & 2015 & 201509 \\
S10 & Mudanjiang, Heilongjiang Province & 2015 & 201510 \\
S11 & Antu, Jilin Province & 2015 & 201511 \\
S12 & Dandong, Liaoning Province & 2015 & 201512 \\
S13 & Hebei Province & 2015 & 201513 \\
S14 & Hulin, Heilongjiang Province & 2015 & 201514 \\
\hline
\end{tabular}

$\times 10^{3} \mu \mathrm{g} / \mathrm{mL}$, and $25.738 \mu \mathrm{g} / \mathrm{mL}$, respectively. The standard solutions were stored at $4^{\circ} \mathrm{C}$ in refrigerator.

\subsection{Preparation of Test Solutions. About $2.0 \mathrm{~g}$ Oviductus} Ranae powder (40-mesh sieve) was accurately weighed and placed in a Erlenmeyer flask. $40 \mathrm{~mL}$ dichloromethane was added to the flask and extracted for 20 min via ultrasonic method with the power of $400 \mathrm{~W}$ and the frequency of $40 \mathrm{KHz}$. The extraction was repeated for three times and filtered. The combined filtrates were concentrated via roller evaporator. The residue was dissolved into $2 \mathrm{~mL}$ of methanol in volumetric flask. The solution was then filtrated through a $0.22 \mu \mathrm{m}$ membrane. The filtrate was regarded as the test solution.

\subsection{Method Validation}

2.5.1. System Adaptability Test. Blank solvent, standard solution, and sample solution of each substance were analyzed based on the chromatographic condition of Section 2.1 and the results showed in Figures 2, 3, and 4.

2.5.2. Liner Range. A series volume of mixed standard solutions was transferred by volume with $5 \mu \mathrm{L}, 10 \mu \mathrm{L}, 15 \mu \mathrm{L}, 20$ $\mu \mathrm{L}, 30 \mu \mathrm{L}, 40 \mu \mathrm{L}, 50 \mu \mathrm{L}$, and $60 \mu \mathrm{L}$ and injected into HPLC, respectively. Chromatogram was recorded and the standard curve was drawn with peak area $(Y)$ as the vertical coordinate and the content of the measured substance $(X)$ as horizontal coordinate. The mixed control solutions were diluted with methanol. The limits of detection (LOD) and the limits of quantification (LOQ) were determined by three times and ten times of the signal noise ratio, respectively.

2.5.3. Precision. An intraday precision test was carried out by the following method. The same mixed control solution was transferred in the same day for six times in a row. RSD\% was calculated according to the chromatographic peak area of the components.
2.5.4. Stability Test. The sample solution was injected into HPLC at $0,2,4,6,8,10,12$, and $24 \mathrm{~h}$ after being prepared and peak area of each component was recorded and RSD\% was calculated.

2.5.5. Repeatability Test. The same batch of Oviductus Ranae drug powder was transferred to prepare six sample solutions in parallel according to method of Section 2.4. The chromatographic peak area of each component was recorded. The content and RSD\% were calculated.

2.5.6. Recovery Test. About $1.0 \mathrm{~g}$ of the same batch of Oviductus Ranae powder was weighed precisely, and then a certain amount of control sample solution was added to the sample according to the proportion of sample content-reference substance $(1: 1)$ to prepare six sample solutions in parallel referring to method of Section 2.3. The six sample solutions were injected into HPLC, respectively, and the peak areas were recorded to calculate average recovery rate and RSD\% of each sample.

2.5.7. Durability Test. The durability test was conducted by two different instruments which were Agilent 1260 and Waters E2695. Three different chromatographic columns were applied including Agilent HC-C18, Eclipse XDB-C18, and Amethyst C18-P $(250 \mathrm{~mm} \times 4.6 \mathrm{~mm}, 5 \mu \mathrm{m})$. Analysis was determined at the flow rate of $2.2 \mathrm{~mL} \cdot \mathrm{min}^{-1}, 2.0 \mathrm{~mL} \cdot \mathrm{min}^{-1}$, and $1.8 \mathrm{~mL} \cdot \mathrm{min}^{-1}$ with the column temperature of $30^{\circ} \mathrm{C}, 35^{\circ} \mathrm{C}$, and $40^{\circ} \mathrm{C}$. The content and RSD\% of the six steroid components in the same batch were calculated. The separation degree of the charmatographic column was investigated. The number of theoretical plates was also investigated

\section{Results and Discussion}

\subsection{Method Validation}

3.1.1. System Adaptability Test. The theoretical plates were selected according to the separation resolution between the analytes and impurities. After several tests of standards and testing samples, we found when theoretical plates are bigger than or equal to 3500 the analytes have good resolution in chromatographic peaks. The results of system adaptability are showed in Figures 2, 3, and 4. The resolutions of 7-hydrocholesteol, 7-ketocholesterol, 4-cholesten-3-one, 7-dehydrogenation cholesterol, cholesterol, and stigmasterol were more than 1.5 and the number of theoretical plates was greater than 3500 .

3.1.2. Liner Range. The results were showed in Table 2. High coefficient of determination values $\left(R^{2}>0.9997\right)$ showed good linearity. LOD and LOQ of six substances were within the range of $0.055-0.100 \mu \mathrm{g} / \mathrm{mL}$ and $2.445-1.001 \times 10^{3} \mu \mathrm{g} / \mathrm{mL}$, which showed a high sensitivity under the established chromatographic condition.

3.1.3. Precision. The results showed that $\mathrm{RSD} \%$ values of the peak area of 7-hydrocholesteol, 7-ketocholesterol, 4-cholesten-3-one, 7-dehydrogenation cholesterol, cholesterol, and 


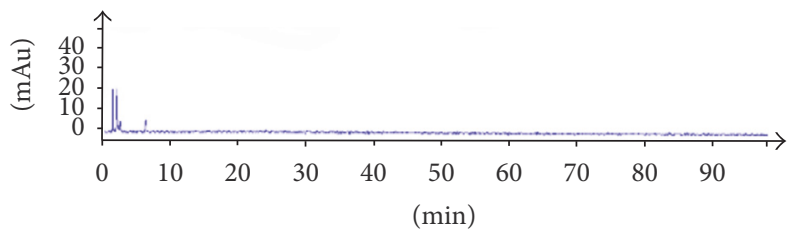

(a)

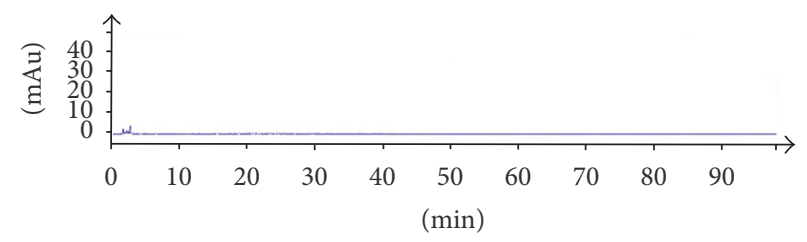

(b)

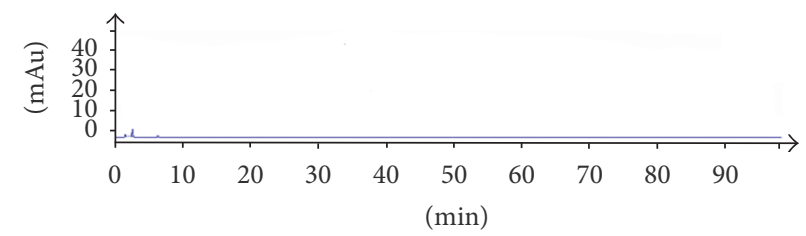

(c)

FIGURE 2: Blank solvent of three detection wavelengths including (a) $205 \mathrm{~nm}$, (b) $240 \mathrm{~nm}$, and (c) $280 \mathrm{~nm}$.

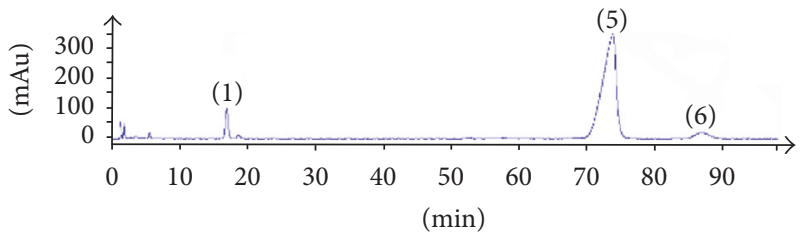

(a)

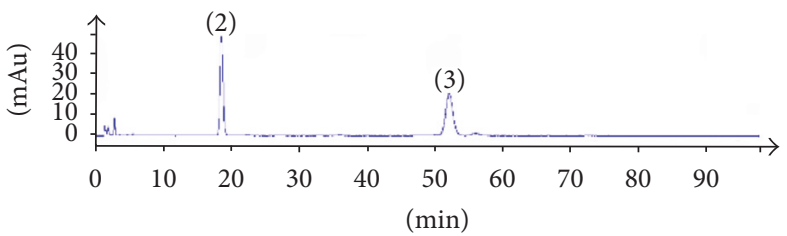

(b)

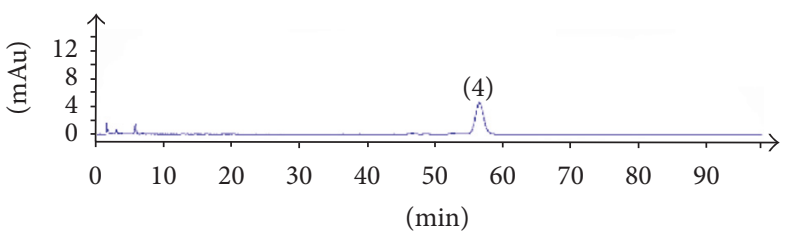

(c)

FiguRE 3: The chromatograms of mixed reference substance ((1) 7-hydroxycholesterol; (2) 7-ketocholesterol; (3) cholest-4-en-3-one; (4) 7dehydrocholesterol; (5) cholesterol; (6) stigmasterol) at three detection wavelengths ((a) $205 \mathrm{~nm}$; (b) $240 \mathrm{~nm}$; (c) $280 \mathrm{~nm}$ ).

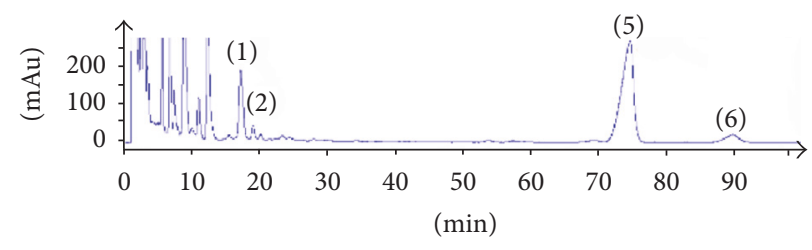

(a)

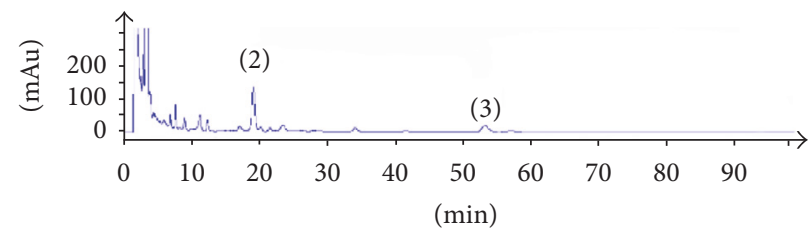

(b)

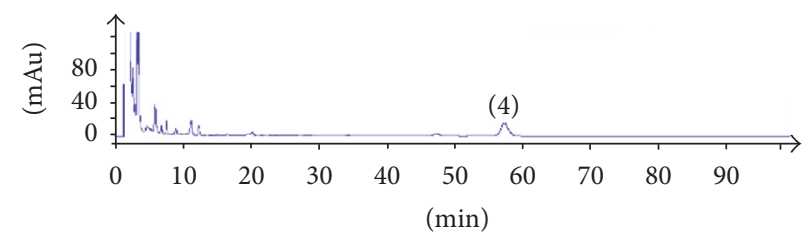

(c)

Figure 4: The chromatograms of test samples ((1) 7-hydroxycholesterol; (2) 7-ketocholesterol; (3) cholest-4-en-3-one; (4) 7-dehydrocholesterol; (5) cholesterol; (6) stigmasterol) at three detection wavelengths ((a) $205 \mathrm{~nm}$; (b) $240 \mathrm{~nm}$; (c) $280 \mathrm{~nm}$ ). 
TABLE 2: The linear equations, coefficient of determination, and linear range of six components.

\begin{tabular}{lccccc}
\hline Substance & Liner equation & $R^{2}$ & Liner range $/ \mu \mathrm{g} / \mathrm{mL}$ & $\mathrm{LOD} / \mu \mathrm{g} / \mathrm{mL}$ & $\mathrm{LOQ} / \mu \mathrm{g} / \mathrm{mL}$ \\
\hline Cholesterol & $y=206.39 x-1.93$ & 1.0000 & $1.00 \times 10^{3}-1.20 \times 10^{3}$ & 0.075 & $1.001 \times 10^{3}$ \\
Stigmasterol & $y=1704.6 x+16.13$ & 0.9997 & $6.43-77.21$ & 0.085 & 6.435 \\
7-Hydrocholesteol & $y=316.9 x+3.13$ & 0.9998 & $39.47-473.70$ & 0.060 & 39.475 \\
7-Ketocholesterol & $y=1094.3 x-0.33$ & 1.0000 & $8.13-97.57$ & 0.065 & 8.130 \\
4-Cholesten-3-one & $y=1120.8 x+1.10$ & 1.0000 & $5.05-60.67$ & 0.055 & 5.055 \\
7-Dehydrogenation cholesterol & $y=620.05 x-0.42$ & 0.9999 & $2.44-29.32$ & 0.100 & 2.445 \\
\hline
\end{tabular}

stigmasterol were $0.5 \%, 0.8 \%, 0.8 \%, 1.1 \%, 0.3 \%$, and $0.5 \%$, which showed a good instrument precision.

3.1.4. Stability Test. The results showed that RSD\% values of the peak area of 7-hydrocholesteol, 7-ketocholesterol, 4cholesten-3-one, 7-dehydrogenation cholesterol, cholesterol, and stigmasterol were $0.9 \%, 0.7 \%, 1.1 \%, 1.0 \%, 0.1 \%$, and $0.4 \%$ (RSD\% $\leq 2.0 \%$ ), indicating that the tested sample solution was stable within $24 \mathrm{~h}$.

3.1.5. Repeatability Test. The results revealed that average mass fraction and RSD\% values of the peak area of 7-hydrocholesteol, 7-ketocholesterol, 4-cholesten-3-one, 7-dehydrogenation cholesterol, cholesterol, and stigmasterol were $74.30 \mu \mathrm{g} / \mathrm{mL}, 17.70 \mu \mathrm{g} / \mathrm{mL}, 7.29 \mu \mathrm{g} / \mathrm{mL}, 5.17 \mu \mathrm{g} / \mathrm{mL}, 3.48 \mu \mathrm{g} /$ $\mathrm{mL}$, and $15.13 \mu \mathrm{g} / \mathrm{mL}$ and $0.6 \%, 0.4 \%, 0.5 \%, 0.9 \%, 1.0 \%$, and $0.8 \%$. The method had good repeatability.

3.1.6. Recovery Test. The results showed that average recovery rate and RSD\% of the peak area of 7-hydrocholesteol, 7-ketocholesterol, 4-cholesten-3-one, 7-dehydrogenation cholesterol, cholesterol, and stigmasterol were $98.0 \%, 98.1 \%, 99.1 \%$ $99.2 \%, 98.3 \%, 98.9 \%$, and $1.3 \%, 1.5 \%, 1.6 \%, 1.0 \%, 0.9 \%$, and $1.5 \%$, illustrating that the method was of good accuracy.

3.1.7. Durability Test. The RSD\% results of mass fractions, determined in all the above conditions, were less than $3.1 \%$, which showed separation effect was good. According to the tests, the determination conditions of six steroidal components in Oviductus Ranae were wide and the method exhibited good durability.

\subsection{Quantitative Analysis of Multicomponents by Single Marker}

3.2.1. Calculation of Relative Correction Factor. In standard curve $Y=a \times X+b, X=(Y-b) / a=Y / a-b / a$, and value of $b / a$ can be ignored when the value of $a / b$ is greater than 100 because the value of $b$ is usually caused by error. At this point, the formula can be directly calculated as $X=Y / a$. Therefore, the relative correction factor can be calculated by the ratio of the slope $(a)$. The relative correction factor calculation formula is shown as follows:

$$
f_{K / S}=\frac{a_{K}}{a_{S}},
$$

where $a_{S}$ is the slope of reference and $a_{K}$ is the slope of the other component to be measured [33]. Cholesterol was selected as an internal reference (1.000) for the quantitative analysis of other five steroids, including 7-hydrocholesteol, 7-ketocholesterol, 4-cholesten-3-one, 7-dehydrogenation cholesterol, and stigmasterol with the detection wavelengths of $205 \mathrm{~nm}, 240 \mathrm{~nm}$, and $280 \mathrm{~nm}$, respectively. The relative correction factors of 7-hydrocholesteol and stigmasterol were 1.5354 and 8.2591 under $205 \mathrm{~nm}$. The relative correction factors of 7-ketocholesterol and 4-cholesten-3-one were 5.3021 and 5.4305 under $240 \mathrm{~nm}$. The relative correction factor of 7-dehydrogenation cholesterol was 3.0043 .

3.2.2. Reproducibility of RCF. In this paper, the effects of two sets of chromatographic systems (Agilent 1260 and Waters E2695), three kinds of chromatographic columns (Agilent HC-C18, Eclipse XDB-C18, and Amethyst C18-P (250 mm $\times 4.6 \mathrm{~mm}, 5 \mu \mathrm{m})$, and different column temperatures and different flow rates on RCF were investigated. Results showed RSDs measured in different conditions were all less than $1.19 \%$. The experiments were repeated by different researchers in different laboratories with the same conditions, and all results showed RSDs were less than $2.0 \%$. indicating the RCF calculated by the established method has good reproducibility.

\subsubsection{Location of Chromatographic Peak of the Measured} Component. The relative retention time was achieved based on the ratio of retention time of measured component $(k)$ and internal standard $(s)$. The formula was shown as follows:

$$
R t_{R}=\frac{t_{R k}}{t_{R s}},
$$

where $k$ is the component to be measured and $s$ is regarded as internal reference cholesterol. The relative retention time between internal reference cholesterol and other components was calculated through formula (2). The effects of different chromatographic systems, column temperatures, and flow rates on RSDs of relative retention time were evaluated. Results showed RSDs of relative retention time between tested components and internal standard cholesterol were less than $0.67 \%$ and the $\mathrm{RSD} \%$ results of durability study were also less than $4.91 \%$. On the other hand, each tested component was scanned via the diode array detector (DAD). 3D absorption spectrum of each compound was obtained, showed in Figure 5. Peak time of each component can be predicted 


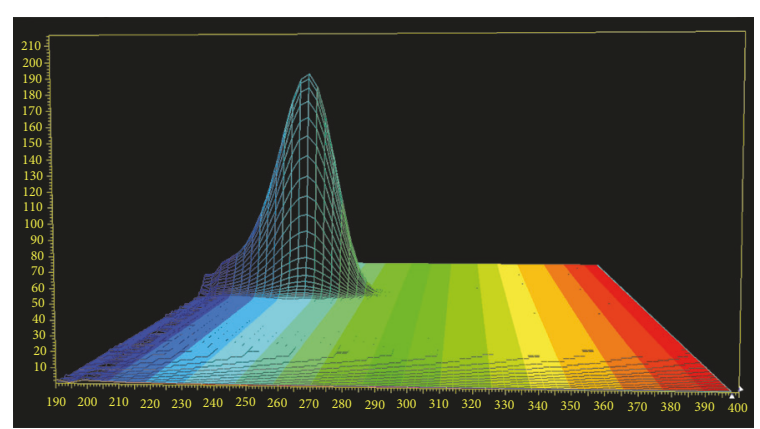

(a)

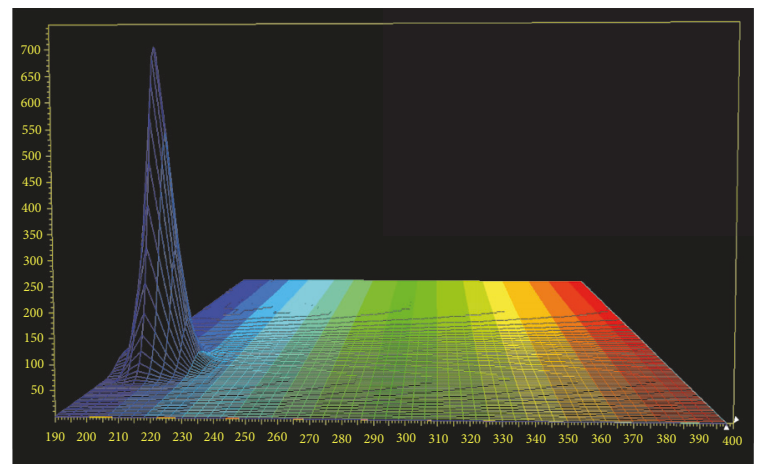

(c)

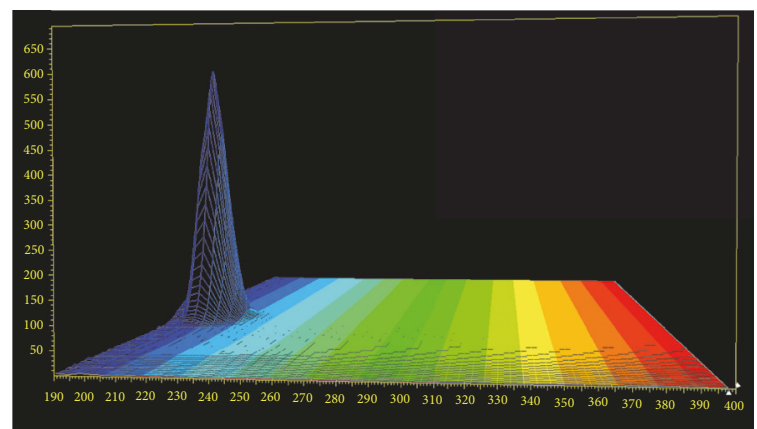

(e)

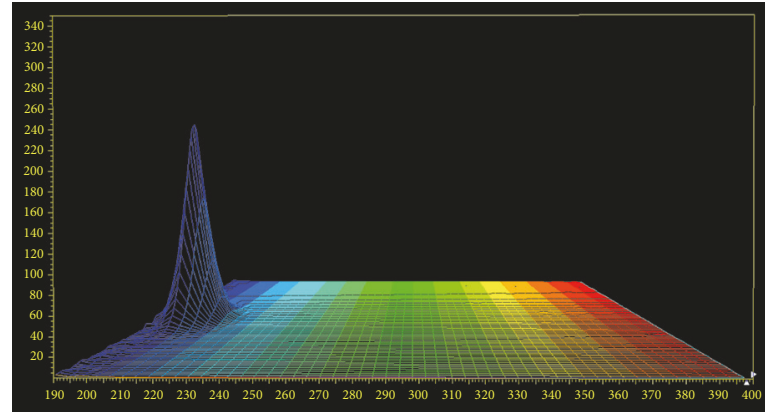

(b)

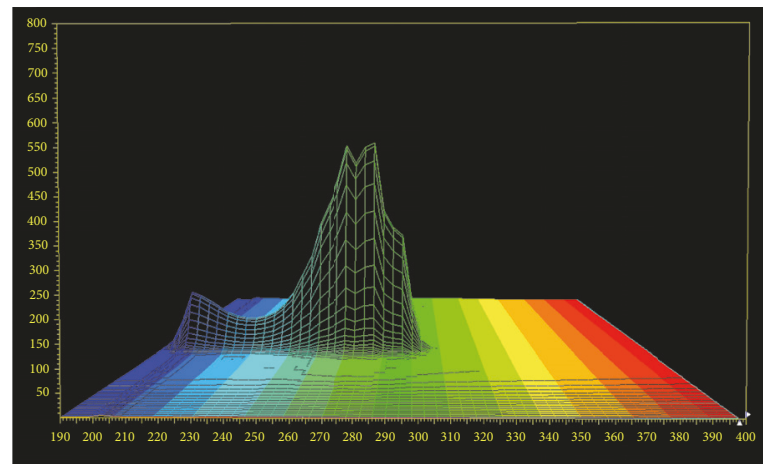

(d)

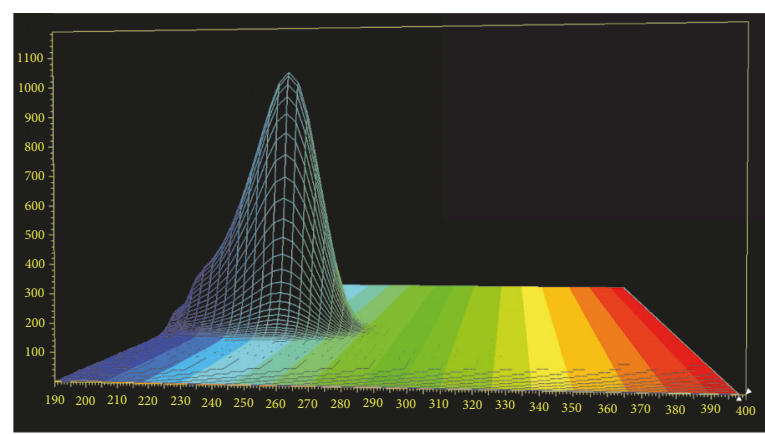

(f)

FIgure 5: (a) Cholest-4-en-3-one, (b) stigmasterol, (c) cholesterol, (e) 7-hydroxycholesterol, and (f) 7-ketocholesterol. 3D absorption spectroscopy of each component.

through the relative retention time, but if other peaks existed near the chromatographic peaks, chromatographic peaks can also be located by overall shape or 3D absorption spectra. Therefore, chromatographic peak can be accurately located in a certain extent by the method established above.

\subsubsection{Comparison of the Results of QAMS Method and Exter-} nal Standard Method. Fourteen batches of Oviductus Ranae powder purchased from different regions were prepared based on the method of Section 2.4. Samples obtained from each region were prepared for two independent copies in parallel and injected into HPLC based on the method of Section 2.1. Subsequently, chromatographic peak area of each tested component was recorded. Then, the content of each component was calculated by the method of ES and QAMS, respectively. Results were shown in Table 3. There were no significant differences between the results of two methods.
In addition, the relative errors were less than $2 \%$, which indicated that the method established above was accurate and reliable.

3.3. Discussion. Cholesterol was selected as the internal reference substance of QAMS method, because cholesterol is one of the main components of Oviductus Ranae with high amount, low price, and easy acquisition. Furthermore, there were no significant differences between the content determination results of QAMS method and ES method when cholesterol was regarded as internal reference material, and the relative error was less than $2 \%$ as well.

In this paper, to obtain a good separation degree, higher theoretical plate number, and good symmetry of chromatographic peak, different mobile phase conditions were investigated for system adaptability test. It was found that the chromatographic peak of all the tested components could 


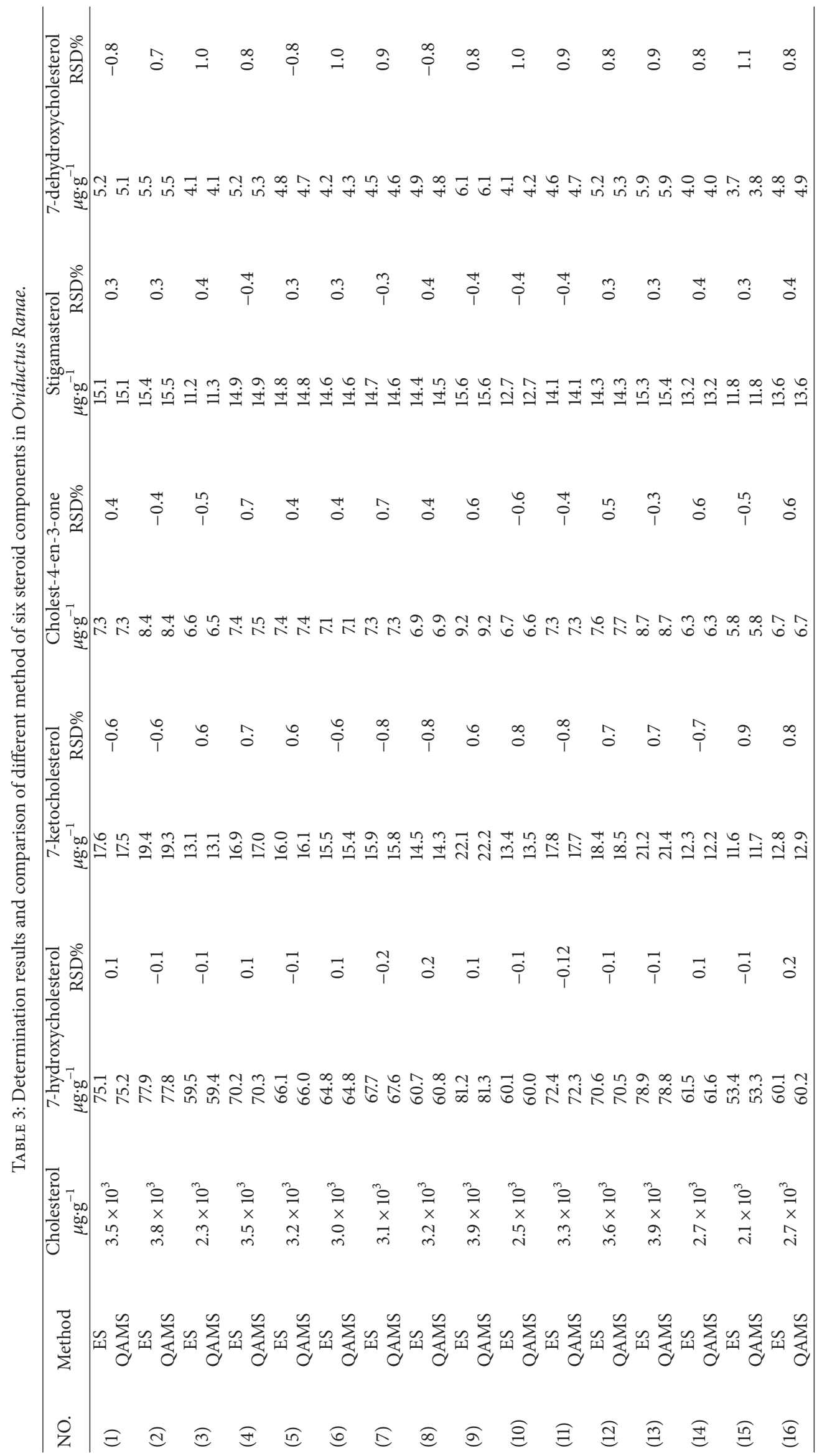


achieve baseline separation with the adjacent peaks using methanol and water $(87: 13 \mathrm{v} / \mathrm{v})$ as mobile phase. To confirm the best preparation method of the tested sample solution, different extraction solvent (methanol, dichloromethane, and chloroform), extraction method (cold soak, ultrasonic, and reflux), amount of the solvent $(30 \mathrm{~mL}, 40 \mathrm{~mL}$, and $50 \mathrm{~mL})$, and extraction time (10 $\mathrm{min}, 20 \mathrm{~min}$, and $30 \mathrm{~min}$ ) were studied. The best preparation process was considered as extracting with $40 \mathrm{~mL}$ dichloromethane for $20 \mathrm{~min}$ via ultrasonic method based on the single factor investigation experiment mentioned above.

It was critical to select suitable detection wavelength for achieving a good separation. The selection of detection wavelength relied on the UV absorption characteristics of the internal reference material and the separation of other components in the test samples. Internal reference cholesterol, 7-hydroxycholesterol, and stigmasterol all exhibited good UV absorption and good separating degree at $205 \mathrm{~nm}$. The wavelength of $205 \mathrm{~nm}$ was regarded as one of the detection wavelengths for the reason above. However, detection of cholest-4-en-3-one and 7-dehydrocholesterol was not sensitive at $205 \mathrm{~nm}$ because of less content in Oviductus Ranae. Thus, based on the characteristics of UV absorption of these two substances, $240 \mathrm{~nm}$ and $280 \mathrm{~nm}$ were selected as the detection wavelengths, respectively. The detection wavelength of cholesterol, 7-hydroxycholesterol, and stigmasterol was $205 \mathrm{~nm}$. The detection wavelength of cholest-4-en-3one and 7-ketocholesterol was determined as $240 \mathrm{~nm}$, and 7dehydrocholesterol was detected at $280 \mathrm{~nm}$.

In this experiment, two kinds of method were investigated including the difference of retention time and relative retention time for locating chromatographic peaks when using cholesterol as internal reference substance. Compared with the results of retention time difference method, the relative retention time was relatively stable, and the RSD\% was less than $4.9 \%$. Thus, the chromatographic peak position can be located according to the relative retention time of chromatographic peaks between tested compounds and internal standard cholesterol, the chromatograms of the overall shape, and the $3 \mathrm{D}$ absorption spectra information of six components in Oviductus Ranae.

\section{Conclusion}

In this paper, HPLC-DAD method was adopted for determination of relative retention time and relative correction factor of six steroids in Oviductus Ranae for the first time. A QAMS method was developed for determining the contents of six kinds of steroidal constituents simultaneously. The QAMS method established in this study has been proved by method validation methodology to be accurate, feasible, and reliable for determination of contents of six steroidal components and can be applied to the quality control of Oviductus Ranae.

\section{Ethical Approval}

This article does not contain any studies with human participants or animal performed by any of the authors.

\section{Conflicts of Interest}

All authors declare that they have no conflicts of interest.

\section{Acknowledgments}

Thanks are due to Jilin University for providing the research offices.

\section{References}

[1] National Pharmacopoeia Committee, The pharmacopoeia of the People's Republic of China, vol. 255, China Medical Science And Technology Press, Beijing: China, 2015.

[2] P. Zhang and J. Y. Yang, "The influence of oviductus ranae on glucose metabolism in mice in sports training," Journal of Hygiene Research, vol. 43, no. 1, pp. 124-127, 2014.

[3] C. S. Lou and J. M. Cao, "Effect of oviductus ranae on testosterone content, substance metabolism and exercise capacity in rats receiving exercise training," Chinese Journal of Experimental Traditional Medical Formula, vol. 20, no. 20, pp. 150-154, 2014.

[4] L. Cao, "The pharmacological research progress of oviductus ranae is outlined," HeiLongJiang Medical Journal, vol. 15, no. 5, p. 384, 2002.

[5] J. L. Xiao and C. Y. Liu, "Research progress of pharmacological effects on rare animal medicine oviductus ranae," Jilin Journal of Traditional Chinese Medicine, vol. 32, no. 7, pp. 751-753, 2012.

[6] Y. S. Wang and Y. H. Cao, "Studies on determination of contents of cholesterol in oviductus ranae," Chinese Traditional Patent, vol. 30, no. 9, pp. 1402-1404, 2008.

[7] Y. S. Wang, The Study on Drug Efficacy Ingredients of Oviductus Ranae and Its Quality Contro Method, Jilin University, Changchun, China, 2007.

[8] J. Liu, S. Liu, and C. C. Liu, "Determination of estradiol in oviductus ranae by HPLC," Liaoning Journal of Traditional Chinese Medicine, vol. 37, no. 1, pp. 138-139, 2009.

[9] C. Yan, Y. Wu, Z. Weng et al., "Development of an HPLC Method for Absolute Quantification and QAMS of Flavonoids Components in Psoralea corylifolia L," Journal of Analytical Methods in Chemistry, vol. 2015, Article ID 792637, 7 pages, 2015.

[10] H. M. Gao, Z. M. Wang, Y. J. Li, and Z. Z. Qian, "Overview of the quality standard research of traditional Chinese," Frontiers of Medicine, vol. 5, no. 2, pp. 195-202, 2011.

[11] X.-Y. Song, Y.-D. Li, Y.-P. Shi, L. Jin, and J. Chen, "Quality control of traditional Chinese medicines: a review," Chinese Journal of Natural Medicines, vol. 11, no. 6, pp. 596-607, 2013.

[12] A. Chen, L. Sun, H. Yuan, A. Wu, J. Lu, and S. Ma, "A holistic strategy for quality and safety control of traditional Chinese medicines by the "iVarious" standard system," Journal of Pharmaceutical Analysis, 2017.

[13] C.-Q. Wang, X.-H. Jia, S. Zhu, K. Komatsu, X. Wang, and S.Q. Cai, "A systematic study on the influencing parameters and improvement of quantitative analysis of multi-component with single marker method using notoginseng as research subject," Talanta, vol. 134, pp. 587-595, 2015.

[14] D.-W. Li, M. Zhu, Y.-D. Shao, Z. Shen, C.-C. Weng, and W.D. Yan, "Determination and quality evaluation of green tea extracts through qualitative and quantitative analysis of multicomponents by single marker (QAMS)," Food Chemistry, vol. 197, pp. 1112-1120, 2016. 
[15] L.-L. Wang, Y.-B. Zhang, X.-Y. Sun, and S.-Q. Chen, "Simultaneous quantitative analysis of main components in linderae reflexae radix with one single marker," Journal of Liquid Chromatography and Related Technologies, vol. 39, no. 8, pp. 422-427, 2016.

[16] G. Kuang, J. Zhou, M. Yao et al., "Systematic study on QAMS method for simultaneous determination of triterpenoid saponins in Ilex pubescens by HPLC and UPLC," Analytical Methods, vol. 7, no. 16, pp. 6579-6587, 2015.

[17] L. Yan, X. Wei, T. Ji et al., "Development of a novel method combining multi-wavelength HPLC fingerprint and quantitative analysis of multi-component by single marker for quality control of Houttuynia cordata," Journal of Chemical and Pharmaceutical Research, vol. 6, no. 8, pp. 347-356, 2014.

[18] C. Zhu, X. Li, B. Zhang, and Z. Lin, "Quantitative analysis of multi-components by single marker-a rational method for the internal quality of Chinese herbal medicine," Integrative Medicine Research, vol. 6, no. 1, pp. 1-11, 2017.

[19] B. Wang, H. S. Shi, and L. Song, "The Physiological Functions of Cholesterol and the Treatment of Hyperlipidemia and Atherosclerosis," China Practical Medicine, vol. 2, no. 25, pp. 5354, 2007.

[20] L. Zhang, Preparation Method for 7-dehydroxycholesterol, Beijing University of Chemical Technology, Beijing, China, 2008.

[21] Y. Q. Wang and W. L. Xv, "Studies on the recrystallization purification and separation of stigamasterol from phytosterols," Journal of Yangzhou University, vol. 5, no. 2, pp. 53-56, 2002.

[22] Y. Yoshida and E. Niki, "Antioxidant effects of phytosterol and its components," Journal of Nutritional Science and Vitaminology, vol. 49, no. 4, pp. 277-280, 2003.

[23] S. Zhang and W. Yue, "Inhibitive effect of Stigmasterol from Hedyotis diffusa willd. On hepatoma cells in vitro and vivo and its influence on transplanted H22 tumor cell's multiplication cycle, apoptosis," Progress in Modern Blomedicine, vol. 8, no. 11, pp. 2016-2017, 2008.

[24] W. Chen, C. Yu, P. Hu, J. Bao, J. Tang, and L. Wu, "Stigmasterol blocks cartilage degradation in rabbit model of osteoarthritis," Acta Biochimica Polonica, vol. 59, no. 4, pp. 537-541, 2012.

[25] A. K. Batta, G. Xu, A. Honda, T. Miyazaki, and G. Salen, "Stigmasterol reduces plasma cholesterol levels and inhibits hepatic synthesis and intestinal absorption in the rat," Metabolism: Clinical and Experimental, vol. 55, no. 3, pp. 292-299, 2006.

[26] K. Suzuki, "Formation of cholest-4-en-3-one by intestinal bacteria and its biological effect. RIKEN Review," Focused on Microbial Diversity, vol. 3, pp. 17-18, 1993.

[27] D. H. Barton, "The invention of chemical reactions: the last five years," ChemInform, vol. 23, no. 29, p. 303, 1992.

[28] K. Wu, W. Li, J. Song, and T. Li, "Production, purification, and identification of cholest-4-en-3-one produced by cholesterol oxidase from rhodococcus sp. in aqueous/organic biphasic system," Biochemistry Insights, vol. 8, 1, pp. 1-8, 2015.

[29] C. F. Lv and Y. L. Chen, "Bioconversion of cholesterol by cholesterol oxidase from Brevibacterium sp," Journal of Wuxi University of Light Industry, vol. 20, no. 5, pp. 485-488, 2001.

[30] A. E. Wakefield, S.-Y. Ho, X.-G. Li, J. S. D’Arrigo, and R. H. Simon, "The use of lipid-coated microbubbles as a delivery agent of $7 \beta$-hydroxycholesterol in a radiofrequency lesion in the rat brain," Neurosurgery, vol. 42, no. 3, pp. 592-598, 1998.

[31] X. B. Cao and S. G. Sun, "Effect of $7 \beta$-hydroxycholesterol on glutamate transporters expression and its mechanism in hippocampus in rats of post traumatic epilepsy," Chinese Journal of Rehabilitation, vol. 20, no. 2, pp. 333-336, 2005.
[32] Y. Saito and N. Noguchi, "7-Hydroxycholestrol as a possible biomarker of cellular lipid peroxidation: difference between cellular and plasma lipid peroxidation," Biochemical and Biophysical Research Communications, vol. 446, no. 3, pp. 741-744, 2014.

[33] B. He and Y. Liu, "Simultaneous determination of 10 constituents in Shuangqing Yanhou Tablets by HPLC-QAMS," Chinese Traditional and Herbal Drugs, vol. 44, no. 8, pp. 974981, 2013.

[34] X. Zhao, Studies on Synthesis of 7-Ketocholesterol and 7 $\beta$ Hydroxycholesterol, Jilin University, Changchun, China, 2010. 

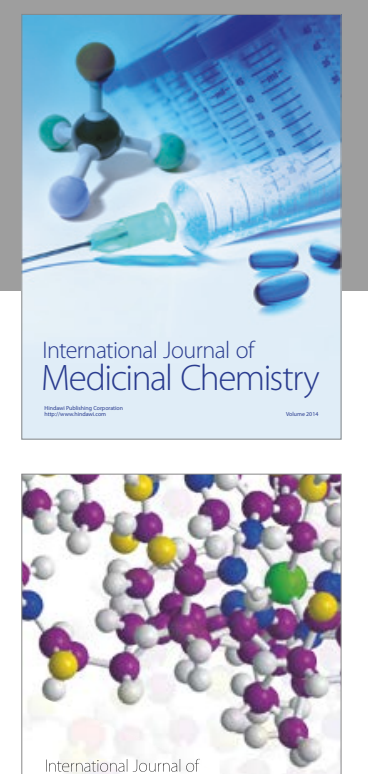

Carbohydrate Chemistry

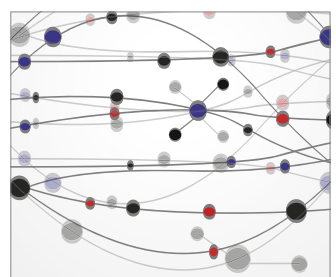

The Scientific World Journal
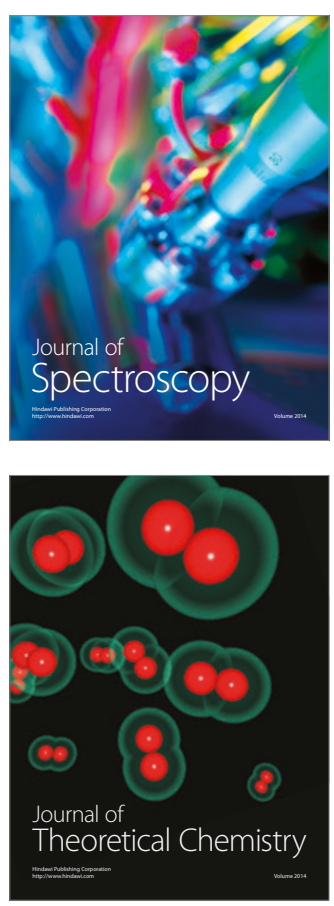
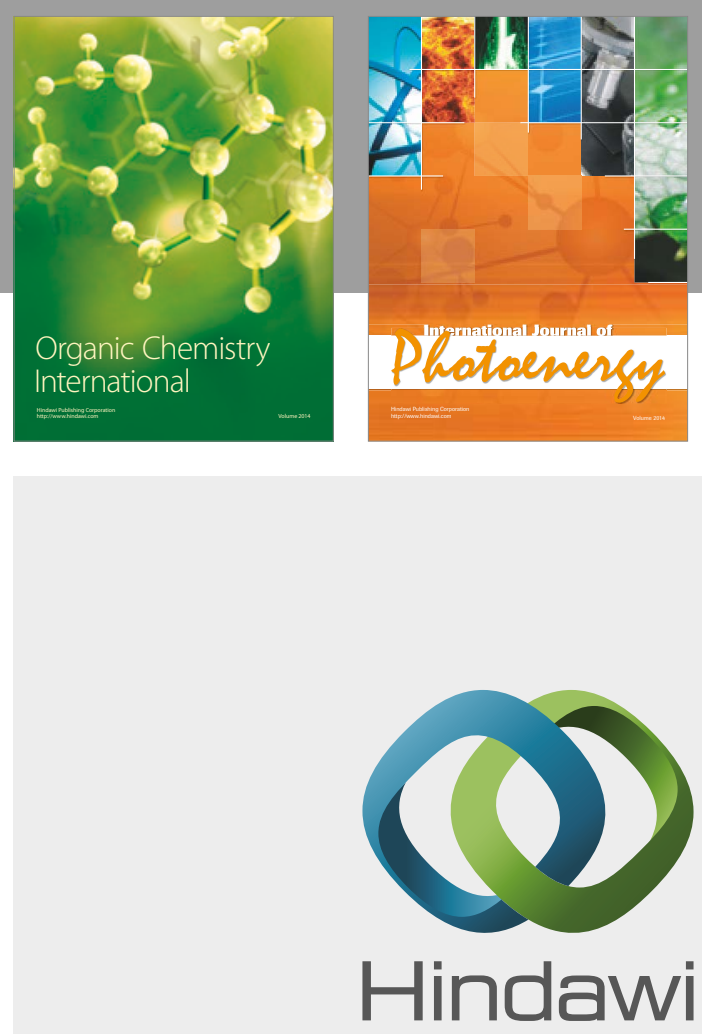

Submit your manuscripts at

https://www.hindawi.com

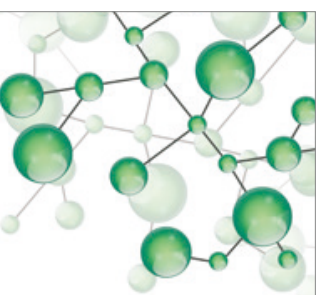

International Journal of

Inorganic Chemistry

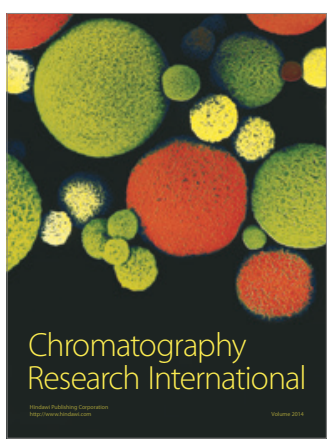

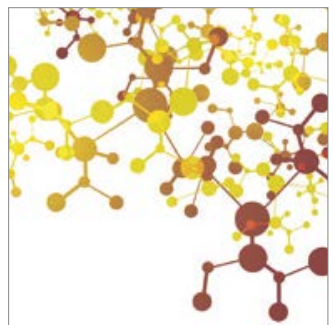

Applied Chemistry
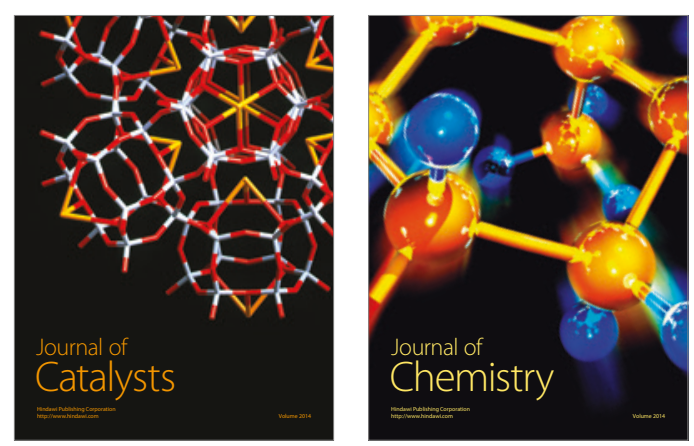
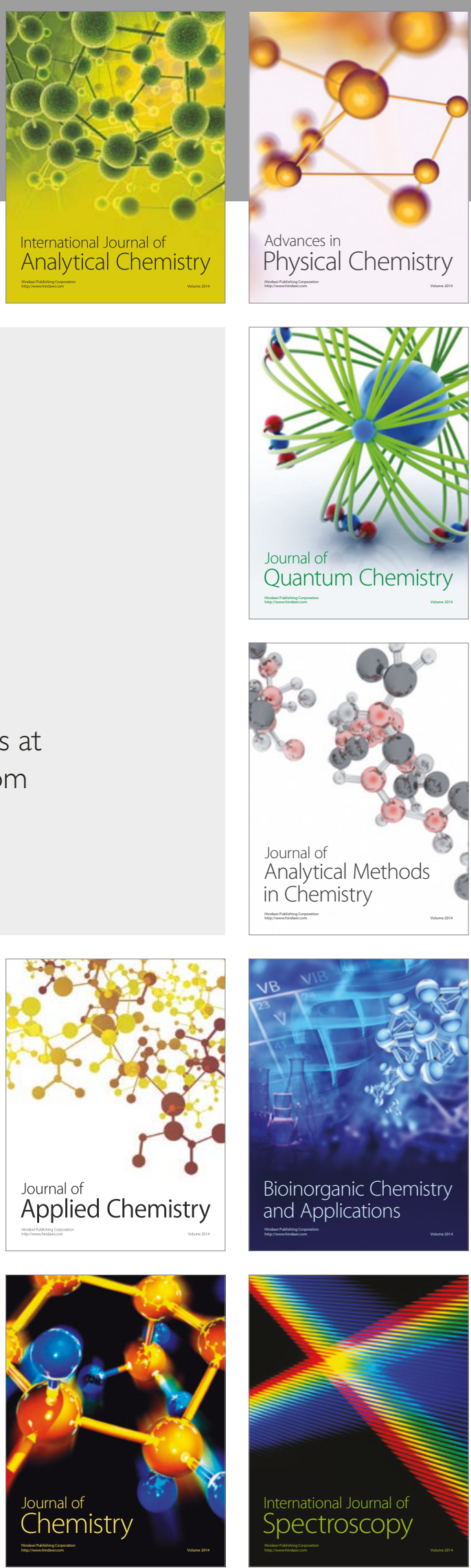